\title{
The Effects of Reflective Teaching Techniques on Teachers' Self- Evaluation for Further Lessons: Analysis through Diary Keeping
}

\author{
${ }^{\mathrm{a}}$ İsmail Çakır (iD and ${ }^{\mathrm{b}}$ İrem Işsk \\ a Ankara Yıldırım Beyazıt University, Ankara, Turkey, icakir@ybu.edu.tr \\ b MA Student, Hacettepe University, Ankara, Turkey, isik.irem@hacettepe.edu.tr
}

To cite this article: Işık, İ. \& Çakır, İ. (2020). The effects of reflective teaching techniques on teachers' selfevaluation for further lessons: Analysis through diary keeping. Focus on ELT Journal

(FELT), 2(1), 20-36. https://doi.org/10.14744/felt.2020.00016

\begin{abstract}
This study aims to reveal the current attitudes and beliefs of English teachers about reflective teaching with an interview along with using a technique called diary keeping. It also focuses on the effects of keeping diaries on teachers' self-reflection and tries to bring the contributions it can provide to teachers' reflective teaching skills into the results of this study. It has been presumed that teachers will benefit the most in this process from this technique that allows them to look at their own practices closely through an introspective, mirror-like experience. For this study, the data were collected from four English teachers and diaries were used as the instrument of this study. Prediary questions were also asked teachers to reveal their current attitudes related to the topic as well as to identify the level of awareness on the topic. The data were analyzed qualitatively by using thematic analysis. It is found out that teachers have used this technique both as a source and as a tool. They have used it as a source of awareness, self-evaluation, and preparation for further lessons and as a tool to analyze student needs, detect routine activities, and uncover the problems. As a result of this study, diaries have been suggested for further educational practices and current English teachers because they lead one of the best ways the teachers can be reflective, give themselves effective feedback and advance their teaching skills.
\end{abstract}

Keywords:

reflection

evaluation

reflective teacher

diary

journal

\section{Introduction}

Reflective teaching has been one of the most prominent areas of teaching pedagogy and teacher education. In many schools and institutions, the majority of English language teachers come to classrooms unaware of the reasons behind their own teaching and practices. It has been discussed for many years that there are different applications of being reflective for teachers and reflective action which may help teachers feel more confident, secure, and content with their teaching and classroom implementations both during the lesson time and for further lessons. English teachers who are reflective can contribute to students' development as well as their own as language teachers since they are always in a process of evaluation. In education, this leads teachers to be critical in their practices and more hardworking to make classroom practices better and more useful for learners. Even experienced teachers might have problems in their teaching career and tend to burn out, which will result in poor performance of both their own and learners. Therefore, 
researchers have also proved that reflection is crucial for teachers since it helps them acknowledge the experience, assume a critical attitude towards practice, enhance their awareness of teaching, develop profound understanding, and create positive changes (Maksimović \& Osmanović, 2019).

Recent changes in education and teacher development in Turkey have brought teachers to a point where they try to understand their students' needs and follow the opportunities to be more professional teachers. To be able to understand how reflective English language instructors are in Turkey, Gözüyeşil and Soylu (2014) investigated EFL instructors through a reflective thinking inventory and found out that one prominent way to understand this is through reflecting on one's own teaching by using one of the reflective techniques to bring changes into their teaching and going beyond their routinized classroom situations. Similarly, Dikilitaş and Yaylı (2018) tried to grasp the changes in the professional identity development of teachers through action research to have a closer look at teachers' selfefficacy beliefs, self-reflection, and awareness. In a mixed-method approach by Moghaddam et al. (2019), journal entries were used with EFL teachers to qualitatively analyze their reflective actions and findings encourage future teachers to have a fresh and closer look at their classroom practices with the intention of changing and modifying the techniques they use in their classrooms. It is stated by Bilger (2017) that 'reflection helps us understand the nature of feelings, our patterns of thoughts, and our emotional reactions' (p.146). Akbaş and Dikilitaş (2019) also stress the value of reflection and argue that 'the learning and teaching experiences and creating personal and pedagogical meanings could empower teachers since it leads to a sense of self-regulation of own learning to become a teacher' (p. 134). Therefore, diary entries were also chosen in this current study to find out the changes and contributions reflective diaries can bring to teachers' classroom practices. It is quite significant to investigate teachers' attitudes and views in a far deeper way by using introspective approaches like journals and diaries. As a result, this study aims to motivate teachers to be reflective by bringing English teachers' reflections on authentic classroom events to the surface.

\section{Literature Review}

Reflective Teaching

Schön $(1983 ; 1987)$ defines reflection as an advanced mental process that goes beyond technical reality and involves an ability to be intuitive and insightful, and is mostly related to action and reflective practice, what he also calls as 'reflection-in-action' and 'reflectionon-action.' Therefore, in educational settings, this kind of reflection results in critical thinking and reflective action of a teacher. For critical reflection, focusing on the problem, defining suppositions related to the problem, inductive and deductive reasoning related to the analysis of the problem, assessment of the credibility of all these suppositions and sources of information, discussion, evaluation, self-regulation, and problem-solving are all the skills a critical thinking person must have (Maksimović \& Osmanović, 2019).

Reflective teachers are defined by Schön (1983) as teachers who critically investigate their classroom practices, bring new ideas related to the way they can improve their performance to enhance students' learning, and carry out those ideas in practice. According to Schön (1983), for the reflection to occur, "there is some puzzling or troubling or interesting phenomenon with which the individual is trying to deal. As the individuals try to make sense of it, they also reflect on the understandings which have been implicit in 
their actions, understandings which they surface, criticize, restructure, and embody in future action" (p. 50).

In a various number of studies, (e.g. Dewey, 1993; Farrell, 2014; Grant \& Zeichner, 1984) three main features of reflective teachers are characterized: 'open-mindedness', which is a willingness to listen to more than one aspect of a problem and give way to alternative ideas and views; 'responsibility' which is thinking carefully about the results an action can lead to; and wholeheartedness which means that teachers can handle ambiguities and fears so as to critically and meaningfully evaluate their practice (Tajik \& Pakzad, 2016). Maksimović and Osmanović (2019) mention that only those teachers who reflect on their practice do become more professional and efficient in teaching since only systematic reflection enables teachers to have an influence on making decisions that may cause changes in teaching practice. Reflective practice also helps teachers free themselves from the constraints of a routine and impulsive behavior (Maksimović \& Osmanović, 2019). As it is pointed out earlier, even experienced teachers are often unaware of their teaching routines and beliefs; consequently, they may not actually do what they think they do in the classroom (Farrell, 1998). There is indeed a big difference between reflective action and routine action, and according to Zeichner and Liston (1987), reflective action "entails the active, persistent and careful consideration of any belief or supposed form of knowledge in light of the grounds that support it and the consequences to which it leads. Routine action is guided primarily by tradition, external authority, and circumstance" (p. 24). It is also crucial to bear in mind that the concept of reflective practice also arose out of the need to counteract burnout in the teaching profession. For example, 'burned out' teachers may see teaching as a routine and find it repetitive (Farrell, 1998). In a study conducted with a novice teacher in Turkey by Kayaoğlu, Erbay and Sağlamel (2016), this aspect of teaching is highlighted by especially emphasizing teachers' feeling reluctant to develop themselves professionally due to the reasons such as busy schedule, institutions' and parents' high expectations and lack of appreciation by any educational authorities. For this reason, it is suggested not to think of even reflective practice as the only effective solution that will work very quickly. On the other hand, Cebeci (2016) found out that when teacher candidates reflected back on their micro-teaching sessions in interviews conducted, they related themselves with positive feelings favoring the curriculum as well as becoming aware of using different teaching techniques and as a result developing their professional competence and enjoying teaching the young learners.

As Zeichner (1998) pointed out, reflective action does not only involve a logical or rational problem-solving process but also involves intuition, emotion, and passion so it is not something that can be neatly packaged as some have tried to do, and taught as a set of techniques for teachers to use. Teachers need to realize and be aware of the need and urge to be reflective in terms of every aspect of their teaching. So, reflective teachers need to sit and analyze carefully about their teaching practices and classrooms especially by asking the broader questions, not only like 'do I like results' but also 'have my objectives been met' (Zeichner, 1998). Therefore, reflective teaching is a term that is broader than the idea of meeting classroom objectives but rather trying to get better results in each try than the previous ones. So, it is a process that always helps the teachers develop and improve their teaching for better outcomes. 


\section{Reflection-in-action}

Schön $(1983 ;$ 1987) puts the reflection into two categories as reflection-in-action and reflection-on-action. When teachers implement their classroom routine and find out that these are not useful or do not work in the new situation, then they instantly need to refer to reflection-in-action to deal with the problem. Farrell (1998) recognizes reflection-in-action as an ability to display problems based on past experiences as if a type of conversation takes place between the unknown situation to be analyzed and the reflective practitioner. That is why, it can be also described thinking while doing the action. Moghaddam et al. (2019) discovered that reflections related to classroom management and learning environment are fairly connected to reflection-in-action since they are related to the way teachers decide to approach situations which are unexpected at the time of the lesson.

\section{Reflection-on-action}

Another aspect of reflection is that if the teachers look back and reflect on what happened in the class, then it means that they adopt reflection-on-action. The fact that teachers take some time and evaluate the events, try to come up with possible solutions for the future shows that they internalize the reflection-on-action approach. Farrell (1998) recognizes reflection-on-action as some kind of metacognitive action seeing that it requires critical thinking and analysis. It is observed in a study by Kayaoğlu, Erbay and Sağlamel (2016) that the novice teacher who was interviewed on her reflections later in the study was mostly in a state of reflection-on-action since she already did the action and was describing them reflectively and then justifying her decisions.

\section{Reflection-for-action}

Other than these two types of reflection, Tajik and Pakzad (2016) mention that in reflection-for-action, teachers reflect not to go back and analyze the past but to guide future action. Teachers can predict possible problems that might occur in the future based on their reflections and accordingly they can change, modify, or arrange their future classroom practices. In a study conducted with pre-service English teachers, Yeşilbursa (2011) points to teachers' reflective skills of contemplating possible solutions for the future or projecting themselves for possible occurrences in the future based on their past experiences. Tülüce and Çeçen (2017) also mention that the student teachers of EFL engaged themselves in a process of reflection-for-action while watching videos of their own micro-teaching lessons and at the same time reflecting and deciding for their future practices.

\section{Diary Studies}

There are many different implementations of reflective action in education and second language learning classrooms. In terms of teachers, there are options like journal/diary writing, peer observation, lesson report forms, audio, or video recording the lessons. One of the most prominent techniques used in recent years has been the journal or diary entries for they are comprehensive while looking back on thoughts and feelings reflected on the events and situations. In this sense, Richards (1991) points out that experience by itself is indeed not enough for professional development, but that experience in collaboration with reflection can be more powerful for teacher development and professional growth. Genç 
(2010) emphasizes the significance of reflection through journal entries and states that the process is a kind of 'eye-opener' since it motivates teachers to help to analyze possible solutions and to feel autonomous and empowered. That is why, providing opportunities for critical self-reflection is valued and recognized as an important component of teacher development (Richards, 1992). Boud, Keogh, and Walker (1985) also contend that experience alone is not the key to learning, and reflection is what turns experience into learning. In a study conducted in Turkey, Yeşilbursa (2011) states that "even through a single written reflection on one microteaching event a good deal of insight can be gained into the way pre-service teachers see themselves as teachers and how they reflect on their own practice" (p. 113). So, diaries can provide opportunities for teachers to self-reflect and develop their teaching for the future and contribute to their teaching experience. Gün (2011) also mentions that when reflection is not practiced but only preached, it is more like something that will not be embraced and as a result, not pursued by the participants.

Bailey (2006) agrees that reflection is valuable when teachers are able to make a critical inquiry into their process of teaching practice by interpreting the data they collect on their teaching and as a result to make necessary changes in their practices and classrooms based on those interpretations. As it is also noted by Gün (2011), being aware is our first step towards being able to change our practice. For this reason, raising awareness and promoting critical thinking are among the reasons diary studies are favored in reflective teaching. Zeichner and Tabachnick (1991) make it clear that reflection might occasionally seem difficult since it is commonly considered to be a private activity, while reflective teaching, like any kind of teaching, is expected to be a public activity. Diaries can be private too but they have outcomes not only related to the diarist but also the other people involved in his or her experience. Therefore, when reflected on and interpreted meticulously, the diaries' scope is no longer narrow and private.

Richards and Lockhart (1996) point out the importance of diaries by saying "it is a teacher's written response to teaching events and serves two purposes: Events and ideas are recorded for the purpose of later reflection. The process of writing itself helps trigger insights about teaching. Writing in this sense serves as a discovery process" (p. 7). According to Bailey (1991), the diarist may be a language teacher or a language learner but the actual characteristic and focus of diaries are being introspective as it means that the diarist studies his own teaching or learning and reflects on it. This way, they can give reports on their own perceptions which are normally hidden or hard to access for an external observer. Bailey (1991) remarks that "introspective methods encompass 'selfreport, self-observation, and self-revealment"” (p. 63). Moreover, Bailey (1991) adds that "introspections are conscious verbalizations of what we think we know" (p. 63). It is also mentioned by Bailey and Curtis (2009) that "diary studies can offer insights into processes that are not otherwise easily accessible or open to investigation and can thus provide useful information to language teachers, learners and researchers. They are based on data generated through personal written records, and those data consist of detailed notes on events, actions, emotions, and thoughts" (p. 70). Similar to the research studies based on teacher diaries and journal entries, Ho and Richards (1993) also studied journals with ten teachers who were in-service TESOL teacher education program at tertiary level to identify the ways journals promote reflective thinking and found out that teachers mainly wrote about the problems they faced in the classrooms and included the techniques and procedures they used. Based on all these studies and ideas, diary-keeping was chosen as the reflective teaching technique to be used in this research. 


\section{Methodology \\ Research Questions}

This study was carried out to reveal the current attitudes and beliefs of English teachers about reflective teaching and to find out whether there are any significant changes after teachers' keeping diaries on their classroom practices. In this regard, the following research questions were asked;

1. What are the teachers' current attitudes and beliefs towards reflective teaching?

2. In what ways can keeping diaries be effective on teachers' views on reflective teaching and to raise their awareness?

3. What are the contributions of diary keeping to teachers' self-evaluation and reflection for further lessons?

\section{Participants}

The participants of this study were volunteers to take part in the research and they were also chosen for the convenience. They are composed of 4 English teachers (1 male and 3 female), 3 of them working at government schools and 1 of them working at a private language course. They all graduated from English Language Teaching departments and had a BA degree. All teachers had 3 years of teaching experience. The age range of the participants is between 24 and 26.

\section{Instruments}

In this study, teacher diaries were used and diary-keeping was implemented with the teachers. The researchers thought that diary-keeping would be one of the best options for language teachers since it is a verbal skill best reflecting the characteristic of language learning and teaching which are also verbal skills. Pre-diary questions prepared by the authors were also asked teachers. Points to be included in the diaries were taken from "reflection questions to guide journal entries" by Richards and Lockhart (1996) and it has been suggested to teachers as guidance while keeping the diaries. As a result, diaries were both developed with the help of "reflection questions to guide journal entries" by Richards and Lockhart (1996) and teachers' own writing style.

\section{Data Collection and Analysis}

Before starting the process, the researchers familiarized the participant teachers with the process and had a warm-up session of writing with them. During this process, teachers shared what they wrote and gave each other feedback. At the same time, the researchers observed the teachers and measured their level of willingness to participate. Participant teachers were eager and paid attention to the feedback given by their peers and the researchers. They chose a grade and a classroom they had been teaching and kept diaries for 6 weeks after every lesson. The points to be included in the diaries were presented to participant teachers, they read the guidelines and they were suggested that they could also include the answers to these questions along with their own ideas and feelings especially by pointing out to the effects of keeping diaries after every writing session. Reflection 
questions to guide journal entries by Richards and Lockhart (1996) were used in this study to guide teacher diaries. Teachers described their classroom moments, included the points by following up the guidelines, and also shared their feelings about keeping a diary at the end of every writing. Pre-diary questions prepared by the authors were asked to participants before starting the whole process to identify the current attitudes and beliefs of the teachers along with their level of awareness on reflective teaching. It was consulted for pre-diary questions to teachers who are experienced in the reflective teaching area along with the university instructors who are dominant in the subject matter and as a result, their approvals indicated that the questions appeared to be appropriate to the study purpose and content area. Pre-diary questions were asked through meetings and phone calls arranged with teachers, and in the end, diaries were examined. The data were analyzed qualitatively with an exploratory design using interpretive and thematic analysis. The content from diaries was analyzed interpretively and the most recurring patterns were presented under a common theme. Each theme was reviewed and named as a title to guide readers and included in the findings with further explanation.

\section{Results and Discussion}

In this study, the focus is mainly on the teachers' perspective on their experiences that have been interpreted from their diary entries and also the effectiveness of teacher diaries. The results obtained from these tools reveal the current attitudes of the teachers towards reflection, and contributions of keeping diaries to their self-evaluation and further lessons.

The findings from the pre-diary interview showed that teachers in common did not know much about reflective teaching practices except the theory in general. They did not know any techniques to be reflective nor they had applied them in their practices. They did not have regular feedback sessions with their students or by themselves, either. All four teachers thought that diaries or journals could be good ways to be reflective and favored the idea of getting better results of one's teaching when it comes to the preference of being reflective.

The participant teachers included in their diaries, their lesson plans in summary, activities they followed, or the moments they wanted to share as well as the changes and contributions they experienced during this process along with their feelings and thoughts about themselves, the class, or the language education in general. When participant teachers handed their diaries, it was seen that they also assessed the effectiveness of the diary technique while keeping the diaries. It has been found out that this reflective teacher technique has mostly been a source as well as a tool for teachers. The findings have been presented in six categories according to the recurring themes identified with some of the illustrative excerpts taken from teacher diaries and interviews.

\section{A Source of Awareness}

It has been prominently seen that teachers have used diaries effectively to understand some points in their teaching practices and that they have been a source of awareness for them. Most of the teachers specify that they realized some certain things while writing diaries, they think that the diaries made them aware of their practices more. Some excerpts to prove this are as follows: 
"Now I realized that I had problems with not the sequences of activities, somehow I managed it, but the classroom management." (Participant 1)

“...it made me realize that students understand better in this way.” (Participant 3)

The findings show that this aspect of diaries is parallel to a finding in a study by KorucuKis and Kartal (2019) since the most noticeable point in the study of student teachers' journals was self-awareness. In this study, teachers are found to be in a process of realization and it is seen that the experience helps them to see the things they could not see and be aware of in the very beginning. Similarly, in a study by Kayaoğlu, Erbay and Sağlamel (2016), a novice teacher gained insight into her own practices and recognized her mistakes which resulted in an increase in her awareness. However, not all teachers used diaries as a source of awareness to see their weak points but also to understand their better sides and useful classroom activities as well as to grasp diaries' benefits thinking positively as can be seen from the excerpts below:

"I realized I do much more than I thought and my lessons weren't that dull and actually they were a kind of fun" (Participant 2)

"This also raised my awareness and helped me to get better for the next lesson..." (Participant 1)

The findings demonstrate that when teachers started keeping their diaries, whether it was positive or negative, they were involved in a process of self-discovery and awareness. This also opened new ways to understand and analyze other issues as mentioned in teachers' sentences related to classroom management, the sequence of activities, the content of the lessons.

\section{A Tool to Analyze Student Needs}

It has been found out that teachers have understood their students' needs better and included some solutions for that in their diaries. While some were thinking over them in terms of the whole classroom needs, some focused on specific students and tried to understand their needs. Some excerpts are as follows:

"During the lesson, they were talking to each other, but I know that we never had group activities today which would be good for this group of students because they participated well enough last week in group work" (Participant 4)

"My students in this class might need to go back since they pointed out that they had problems with the other teacher at the beginning of the term." (Participant 1)

These findings indicate that some teachers analyzed the needs and the problems especially by referring to 'a certain group of students' and included phrases like 'my students in this class' or 'this group of students' which shows that the teachers carefully struggled to understand the certain groups of students from a minority in a class to a whole different class they are supposed to teach in that term. 
One teacher even focused on affective factors and mentioned her attempt to integrate herself with her student's feelings. This also proves that the teacher recognized her student very well in this sense and owned the problem in the situation as her own fault:

"I think I could not give him enough encouragement because if he fails, he is easily lost." (Participant 1)

In a study conducted by Genç (2010), she mentions that one teacher decided to act considering the specific needs of the students along with their interest and age which finally helped her to implement a certain method according to these needs. Similar to this finding, one of the teachers identified the problem specifically focusing on the level of the students:

"I still thought that I might have chosen a difficult song which was not suitable for their level." (Participant 3)

The statements reveal that teachers have been analyzing the classroom needs whenever they discover them in their diaries. It proves that this aspect of the diaries can also help teachers to uncover these needs and find some concrete solutions by creating a better learning atmosphere in harmony with learners' needs.

\section{A Source of Self-Evaluation}

It has been found out that teachers often evaluated themselves in their diary entries and mentioned in their views, the contributions of this technique to see their strong and weak sides as language teachers. Consciously or unconsciously they were giving themselves feedback and trying to understand themselves as language teachers. This process has helped them to identify their strong and weak points. All the findings from similar studies (Yeşilbursa, 2011; Bilger, 2017; Tülüce \& Çeçen, 2017; Korucu-Kis \& Kartal, 2019) are compatible with the results of this study in terms of the fact that reflective teaching practices help teachers identify their strengths and weakness. Some excerpts provided are as follows:

"I thought I wasn't a good teacher. But I realized that I am not that bad. And I feel more encouraged. If I didn't keep a diary, I wouldn't realize my better sides. " (Participant 2)

"It helped me to see my positive and negative sides. It kind of helped me to see the missing points and useful points in my teaching." (Participant 4)

Based on these statements from teacher diaries, it is seen that teachers have been using phrases of self-evaluation such as 'strong sides' or 'weak points' and they have mainly focused on assessing themselves as language teachers to be able to reach to the success point or become the successful teacher image on their minds. However, teachers recognized the diaries more than the source of identifying strengths and weakness, they also described lacking a certain characteristic to have an efficient lesson that day. They evaluated themselves by also evaluating the results of the lesson and identified the problematic areas such as classroom or time management: 
"I don't have any ideas about how to prevent this. I see, once again that I am not good at classroom management in this grade." (Participant 3)

"I had time management problems since I could not put into practice half of the plan and the materials I prepared.” (Participant 1)

Unlike a study by Dikilitaş and Yaylı (2018), teachers were far beyond self-criticism impulsed by dissatisfaction with themselves, instead, they chose to be positive and remarked often that they were doing more than they thought and came with constructive attributes. One teacher even made it comprehensible by explaining that seeing her good work increased her motivation. This study naturally proves that not all the time focusing on negative points or inabilities will foster change for better, but seeing the positive and strong sides of oneself can be a significant impetus for professional development:

"Writing all those activities that I did today... Thinking of them now, good job, I say. It is increasing my motivation for the next week. I love this class though...” (Participant 1)

"We had fun today a lot, I did not know I could understand the nature of young learners a lot. We had storytelling, dramas, games on the smartboard. Most of them work when they understand and I make myself clear...

...I think I was a bit cruel to myself by judging myself and keep saying: 'I am not a good teacher, I am not a good teacher..." (Participant 2)

Findings show that the self-appreciation seems like a great stimulus to teachers. Selfevaluation with the participants of this study comes with identifying all points not only the negative ones but also the positive ones which keep their mindset healthy and their motivation high.

\section{A Tool to Detect Routine Activities}

While keeping the diaries, it has been found that teachers have detected what they have been repeating unnecessarily and some even explored that they never used certain activity types even if they are suitable with the needs of their learners. Identifying these same and repeated more than necessary types of activities led teachers to choose different types of activities in further lessons and expand their repertoire with diversity. An excerpt from teacher diaries to demonstrate this:

"I have been using act-out and guessing activities again and again for three weeks. Students do not prefer and like them as they used to at the beginning of the term." (Participant 2)

As is obvious from the excerpt above, the teacher has become aware of the type of activities she has used and this has clearly shown her the routine she has been following and the repetitive activity she has used unnecessarily. Moreover, by looking at the other statements, it is also found out that the teachers have brought new and different ideas in their diary reflections based on their thoughts about repetitions or the routine activities. The studies by Genç (2010) and Korucu-Kis and Kartal (2019) also show that teachers are aware of their routines or useless activities when reflecting and try to find out alternatives 
to their teaching techniques. Examples below prove that the teachers project what to do as alternatives:

"I spent most of my class time to ask and answer part as I did the other weeks. I should change it and find a different type of activity which is fun, too." (Participant 2)

"I repeated the same activities most of the time, they were so similar and students got bored. They were all verbal, maybe I should bring some visuals or include TPR in my lesson plan." (Participant 4)

"It is complementary with our needs but I never used roleplays in this topic. I think I really need to plan it well and implement it in the classroom." (Participant 1)

The findings also demonstrate that teachers suddenly engage themselves in a process of reflection-for-action which is another effective aspect of keeping diaries and prepares them for further lessons. This issue will also be discussed below in detail in this study.

\section{A Source of Preparation for The Next Lesson}

It has been observed that teachers have included ideas in diaries for the next lessons with the experiences they had from the previous lessons. This process facilitated to pre-plan and design the next lesson and also made teachers prepared for anything that can possibly occur in the classroom. They wanted to shape their future lessons and make them better by introspecting the situations or moments they had in the classroom and the points they found unsatisfactory or incomplete. New perspectives of teachers showed that they benefited from writing on diaries since it made easier to compare what was done in the previous lessons with their projects on their minds and finally come up with better ideas:

"I was looking at my experience I had in the previous lesson more critically and getting better prepared for the next lesson as a result." (Participant 4)

"In terms of classroom management, I could see my faults and, in this lesson, I can be more careful in the next lesson." (Participant 3)

Statements also show that teachers were engaged in a process of reflection-for-action most of the time. One of the characteristics of diaries is able to see the action that has happened in front of oneself on a paper concretely and then reflecting, making decisions, and projecting ideas on mind for the next action. In the study by Korucu-Kis and Kartal (2019), student teachers engaged themselves in a similar activity and could provide logical responses to emerging issues out of their teaching. Again, very similar to the findings of this study, Yeşilbursa (2011), Tülüce and Çeçen (2017) found out that student teachers were occasionally preparing themselves for the possible future experiences and try to understand them by reflecting on past experiences. In this study, teachers also demonstrated their motivation to have different ideas for the future and constantly attempted to find alternatives:

“...next time, I should not forget to come up with better ideas to raise classroom energy and have fun all together. " (Participant 1) 
"Next time, I will take notes with the minutes of the activities also by considering the possible situations that might take up my time. (Participant 1)

"But I guess I need to find something to make the book activities more fun next week." (Participant 2)

The results show that based on their previous experiences, teachers have preferred shaping their next lessons for better learning outcomes by reflecting on what they have been doing and what they ideally want to achieve for the further lessons. In a constantly changing world, the fact that teachers want to change their approaches or try to find alternatives that are new also produces proof for the impact of reflective practices.

\section{A Tool to Uncover Problems}

It is seen that diaries helped teachers to reveal the most problematic areas or aspects of the lesson. It also paved the way for possible solutions to these problems since teachers could see them on a paper in front of them and this facilitated thinking over and easily interpreting them. An excerpt from teacher diaries is as follows:

"Students were unhappy and less active. I learned at the last minute that they fought in the previous lesson. I should observe the class carefully and talk about these issues at the start of the lesson maybe I can help them and cheer them up a bit." (Participant 2)

Interestingly, the most problematic issues to solve in almost all teachers' diaries come to the point of classroom management. Similarly, in many studies conducted recently (e.g. Genç, 2010; Korucu-Kis \& Kartal, 2019; Moghaddam et al., 2019) teachers include the problems of classroom management in their journal entries or reflective teaching practices. Outstandingly, teachers in this study discovered solutions, some of them might have been the repetitions of their ideas during the class moments which naturally would engage them in a process of reflection-in-action and some of them might have been their decisions when they made while writing in their diaries and contemplating of implementing for the next lessons which would obviously engage them in a process of reflection-for-action:

"There had been a serious problem with a group of students making noise and distracting each other for weeks. For the other lessons, I will change their seats and suggest the classroom teacher do the same." (Participant 3)

"Also, next time, I should not allow him to sit in the same place, that also motivates him." (Participant 1)

All the statements from these findings clearly reveal that the hidden or unseen problems are easily uncovered in teacher diaries. This aspect of the diaries helps teachers to find effective solutions for certain problematic situations especially with respect to classroom management since they could see them more concretely on papers thanks to the reflections in their diaries. 
All these findings from the study reveal that they are very similar to previous research studies alongside the different characteristics of this study. Moreover, there is a consistency in the results with the studies conducted especially in Turkish context (Genç, 2010; Yeşilbursa, 2011; Kayaoğlu, Erbay \& Sağlamel, 2016; Bilger, 2017; Tülüce \& Çeçen, 2017; Dikilitaş \& Yayl1, 2018; Korucu-Kis \& Kartal, 2019). Besides, in the study conducted by Ho and Richards (1993), the topics teachers wrote about the most are related to self-awareness, evaluating teaching and lessons, diagnosing the problems and solutions to them, very similar to the findings of this study which are mostly related to selfevaluation, awareness, and identifying problems.

In the studies by Kayaoğlu, Erbay and Sağlamel (2016) and Korucu-Kis and Kartal (2019), time and busy schedules of teachers have been mentioned as problems and obstacles preventing teachers from continuing their reflective practices. Similarly, teachers in this study mentioned that writing diaries was taking their time or lacking time hinders them giving some more details about the events:

"I really like writing this teaching diary. But I had to keep it short today and could not give details because I did not have enough time this week.” (Participant 2)

“...writing the diary takes a lot of time, too." (Participant 3)

On the other hand, diaries generally helped teachers discover many aspects of their teaching, and consider critically about possible solutions or alternatives. One of the findings that are quite useful and significant in the study is the way teachers approach the problems of which the sources are not themselves but the other people, materials, or authorities. In a critical reflection study by Watts and Lawson (2009), beginning teachers have been found out to adopt an ego-centric and low-level reflection, which resulted in showing negativity and likelihood to blame others for incapabilities. On the contrary, teachers in this study, despite being not experienced enough, showed positive attitudes, and adopted a solution-oriented approach instead of complaining or blaming others. Some excerpts below from teacher diaries prove this:

"Even if I do not use it all the time, the book that was chosen by the headmaster is boring for students. I think, I, with the other teachers, need to suggest something different for the next term." (Participant 1)

"The book of 2nd graders could have been better but every year, it seems like it is the same book. Fortunately, I have an archive of materials for young learners. If I do some extracurricular activities, it will not be difficult for my students because the book is already too easy." (Participant 2)

Based on all these findings from teachers' diary entries, it has been found out that writing has greatly helped participant teachers to discover about themselves as language teachers, their students along with their needs, the materials used and problems related to them, critical thinking, and creating alternatives. Therefore, reflective practices are significantly 
suggested to language teachers to make effective use of diary or journal entries to contribute to their professional development.

\section{Conclusion}

The aim of this study was to examine the effectiveness of keeping diaries on teachers' reflective teaching skills, teachers' views on this technique, and how this technique contributes to their awareness as a language teacher, self-evaluation, and reflection for further lessons. This study proved that teachers greatly benefited from this process of reflection. Being reflective and writing it down helped them to realize what they were doing in the classroom and analyze their practices more critically. It gained them an awareness of self, of their teaching, and effective language teaching in general by reflecting back on their own memories and classroom implementations. It demonstrated that teachers regarded the reflective diary technique in a positive sense and as something that they could use to embody the classroom spirit since everything seemed more concrete on papers. When their answers from pre-interview are compared to what they found and realized while keeping their diaries, their perceptions have changed and even they remarked that this process changed their practices positively and contributed to their teaching.

The only common problem they had with keeping a diary was lacking time. When they did not have time, they mentioned that they could not write and reflect efficiently. They also think that the reason why most of the teachers do not prefer being reflective can be related to not having enough time or not giving priority to this kind of activity. However, this was the only negative point they included in their answers. On the contrary to this aspect, it helped teachers to identify the needs and problems of their students and in the classroom overall, as well as to give themselves feedback in a more realistic way. Moreover, with the evaluation of their teaching and practices, they pre-planned and prepared their further lessons more effectively and securely. Very similar to the findings of the study by Genç (2010), teachers have gained autonomy while making decision for their classrooms. Throughout the process, teachers mostly regarded the reflectivity in a positive sense and the results of the study created positive changes, too which, in this sense, corroborates the other studies in the field (Genç, 2010; Yeşilbursa, 2011; Gözüyeşil \& Soylu, 2014; Kayaoğlu, Erbay \& Sağlamel, 2016; Bilger, 2017; Korucu-Kis \& Kartal, 2019). Differently from the studies conducted in the same field by using different techniques such as videorecording where individuals learn from seeing the evidence (Tülüce \& Çeçen, 2017) or peer observation and interviews where individuals learn from each other (Cebeci, 2016), the participants in this study learned from their own self-talk and faced their memories on the notebooks in front of them which are all powerful ways of learning by referring to narratives and verbal sources such as diaries and journals. Another significant characteristic of this study has been the fact that it paved the way for teachers to engage themselves in all three processes of reflection (reflection-in-action, reflection-on-action, reflection-for-action). Therefore, it is suggested for teachers, institutions and government schools that they can start using any technique to be reflective but especially, reflection papers, journals, and diaries can make them aware of what they have been doing in a more perceptible way. 


\section{Limitations}

It needs to be stated that this study has limitations such as the time allocated to diaries and the number of participants. It is suggested that any similar further research needs to be conducted with more participants and time to provide richer data and more findings. If diaries can be used throughout a term or one academic year, a richer discourse composed of teacher reflections can be obtained and more can be contributed to the field. It is important to note that any similar projects can be triangulated to have richer and more reliable data by using more than one reflective teaching technique such as videorecordings, peer observations along with journal entries.

\section{Disclosure Statement}

No potential conflict of interest was reported by the authors.

\section{References}

Akbaş, E., \& Dikilitaş, K. (2019). Developing critical reflection practices via reflective writing for preservice language teachers. In Inquiry and Research Skills for Language Teachers (pp. 125-135). Palgrave Macmillan, London. https://doi.org/10.1007/978-3-030-21137-0_7

Bailey, K. M. (1991): "Diary studies of classroom language learning: The doubting game and the believing game", in Language acquisition and the second/foreign language classroom, Anthology Series 28, Sartono, E. (coord.), Singapore, SEAMEO Regional Language Centre, 60-102.

Bailey, K. M. (2006). Language teacher supervision: A case-based approach. Cambridge: Cambridge University Press.

Bailey, K. M., \& Curtis, A. (2009). Diary Studies. OnCUE Journal, 3(1), 67-85.

Bilger, N. (2017). Appraisal in preservice teachers' reflections on microteaching experience. ELT Research Journal, 6(1), 138-153.

Boud, D., Keogh, R., \& Walker, D. (1985). Reflection, turning experience into learning. London: Kogan Page.

Cebeci, N. (2016). Prospective teachers' beliefs about micro-teaching. ELT Research Journal, 5(1), 60-71.

Dikilitaş, K., Yaylı, D. (2018). Teachers' professional identity development through action research. ELT Journal, 72(4), 415-424.

Farrell, T. S. C. (1998). Understanding reflective teaching. Teaching and Learning, 19(2), 52-63.

Genç, Z. S. (2010). Teacher autonomy through reflective journals among teachers of English as a foreign language in Turkey, Teacher Development, 14(3), 397-409.

Gözüyeşil, E., Soylu B. A. (2014). How reflective are EFL instructors in Turkey?. Procedia - Social and Behavioral Sciences, 116, 23 - 27.

Gün, B. (2011). Quality self-reflection through reflection training. ELT Journal, 65(2), 126-135.

Ho, B., \& Richards, J. (1993). Reflective thinking through teacher journal writing myths and realities. Prospect, 8(3), 7-24.

Kayaoglu, M. N., Erbay, S., \& Saglamel, H. (2016). Gaining insight into a novice teacher's initial journey through reflective practice. Reflective Practice, 17(2), 167-181.

Korucu-Kis, S., \& Kartal, G. (2019). No pain no gain: reflections on the promises and challenges of embedding reflective practices in large classes. Reflective Practice, 20(5), 637-653. 
Maksimović, J., \& Osmanović, J. (2019). Perspective of cognitive thinking and reflective teaching practice. International Journal of Cognitive Research in Science, Engineering and Education (IJCRSEE), 7(2), $1-10$.

Moghaddam, R. G., Davoudi, M., Adel, S. M. R., Amirian, S. M. R. (2019). Reflective Teaching Through Journal Writing: a Study on EFL Teachers' Reflection-for-Action, Reflection-in-Action, and Reflection-on-Action. English Teaching \& Learning https://doi.org/10.1007/s42321-019-00041-2

Richards, J. C. (1991). Towards Reflective Teaching. The Teacher Trainer, 5(3), 4-8.

Richards, J. C., \& Lockhart, C. (1994). Reflective teaching in second language classrooms. Cambridge: Cambridge University Press.

Richards, J. C., \& Lockhart, C. (1992). Teacher Development through Peer Observation. TESOL Journal, 1(2), 7-10.

Schön, D. A. (1983). The reflective practitioner: How professionals think in action. New York: Basic Books.

Schön, D. A. (1987). Educating the reflective practitioner: Toward a new design for teaching and learning in the professions. San Francisco: Jossey-Bass.

Tajik, L., \& Pakzad, K. (2016). Designing a Reflective Teacher Education Course and its Contribution to ELT Teachers' Reflectivity. Australian Journal of Teacher Education, 41(9).

Tülüce, H. S., Çeçen, S. (2017). The use of video in microteaching: affordances and constraints. ELT Journal, 72(1), 73-82.

Watts, M., \& Lawson, M. (2009). Using a meta-analysis activity to make critical reflection explicit in teacher education. Teaching and Teacher Education, 25, 609-616.

Yesilbursa, A. (2011). Reflection at the interface of theory and practice: An analysis of pre-service English language teachers' written reflections. Australian Journal of Teacher Education, 36(3), 50-62.

Zeichner, K. M., Liston, D. P. (1987). Teaching student teachers to reflect. Harvard Educational Review, 56(1), 23-48.

Zeichner, K. M., Liston, D. P. (1996). Reflective Teaching: An Introduction. Lawrence Erlbaum Associates, Mahwah, New Jersey.

Zeichner, K. M., \& Tabachnick, B. R. (1991). Reflections on reflective teaching. In B. R. Tabachnick \& K. M. Zeichner (Eds.), Issues and practices in inquiry-oriented teacher education (pp. 1-18). New York: Falmer Press.

\section{Appendix 1: Pre-Diary Interview Questions}

1. What do you know about reflective teaching?

2. Do you know any techniques teachers use to be reflective?

3. If so, have you ever applied any of those techniques in your teaching life?

4. What do you think can be useful in terms of being reflective and using techniques such as journal writing or diary keeping?

5. What do you think about teachers' preference for being reflective?

6. What do you think about teachers' preference for not being reflective?

7. Feedback is one of the first steps in being reflective. Do you evaluate and give yourself feedback after the lessons (in a non-written way) or do you let your students give feedback verbally at the end of every lesson?

Appendix 2: Reflection questions to guide journal entries (Richards \& Lockhart, 1996)

Questions about what happened during a lesson: 
Questions about your teaching

1. What did you set out to teach?

2. Were you able to accomplish your goals?

3. What teaching materials did you use? How effective were they?

4. What techniques did you use?

5. What grouping arrangements did you use?

6 . Was your lesson teacher dominated?

7. What kind of teacher-student interaction occurred?

8. Did anything amusing or unusual occur?

9. Did you have any problems with the lesson?

10. Did you do anything differently than usual?

11. What kinds of decision making did you employ?

12. Did you depart from your lesson plan? If so, why? Did the change make things better or worse?

13. What was the main accomplishment of the lesson?

14. Which parts of the lesson were most successful?

15. Which parts of the lesson were least successful?

16. Would you teach the lesson differently if you taught it again?

17. Was your philosophy of teaching reflected in the lesson?

18. Did you discover anything new about your teaching?

19 . What changes do you think you should make in your teaching?

Questions about the students

1. Did you teach all your students today?

2. Did students contribute actively to the lesson?

3. How did you respond to different students' needs?

4. Were students challenged by the lesson?

5. What do you think students really learned from the lesson?

6. What did they like most about the lesson?

7. What didn't they respond well to?

Questions to ask yourself as a language teacher :

1. What is the source of my ideas about language teaching?

2. Where am I in my professional development?

3. How am I developing as a language teacher?

4. What are my strengths as a language teacher?

5. What are my limitations at present?

6. Are there any contradictions in my teaching?

7. How can I improve my language teaching?

8. How am I helping my students?

9. What satisfaction does language teaching give me?

\section{Copyrights}

Copyrights for the articles are retained by the author(s), with first publication rights granted to the Journal.

This is an open-access article distributed under the terms and conditions of the Creative Commons Attribution license (CC BY-NC-ND). http://creativecommons.org/licenses/by-nc-nd/4.0/ 